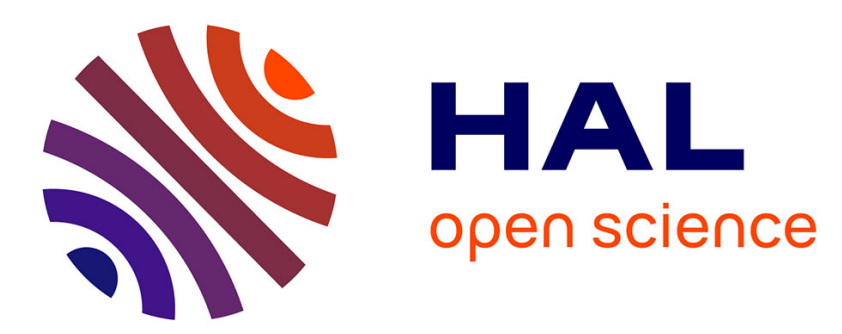

\title{
The speed of experience: the co-narrative method in experience economy education
}

Jerzy Kociatkiewicz, Monika Kostera

\section{To cite this version:}

Jerzy Kociatkiewicz, Monika Kostera. The speed of experience: the co-narrative method in experience economy education. British Journal of Management, 2012, 23 (4), pp.474 - 488. 10.1111/j.14678551.2011.00777.x . hal-02423780

\section{HAL Id: hal-02423780 \\ https://hal.science/hal-02423780}

Submitted on 25 Dec 2019

HAL is a multi-disciplinary open access archive for the deposit and dissemination of scientific research documents, whether they are published or not. The documents may come from teaching and research institutions in France or abroad, or from public or private research centers.
L'archive ouverte pluridisciplinaire HAL, est destinée au dépôt et à la diffusion de documents scientifiques de niveau recherche, publiés ou non, émanant des établissements d'enseignement et de recherche français ou étrangers, des laboratoires publics ou privés. 


\title{
The Speed of Experience: The co- narrative method in experience economy education
}

\author{
Jerzy Kociatkiewicz \\ Essex Business School, University of Essex \\ kociak@kociak.org \\ Monika Kostera \\ University of Warsaw \\ monika@kostera.pl
}

\begin{abstract}
In this text we propose a management learning technique we name the co-narrative method. We see in this approach a useful means for capturing the subtler nuances of experience economy interactions, as well as learning ethics and CSR by nurturing empathy and compassion. We present a method based on the example of the idea of slow as fast side of organizational and festival experiences, which we explored through autoethnographic studies of participation in experience economy events. It builds upon the insights on improving management education through the use of the humanistic approach. The co-narrative method, as we call it, is based on a syzygic mode uniting the two oppositions (while preserving their inherent contradictions). It encourages its users to exercise understanding for the experience of the Other while teaching about concrete cases and events.
\end{abstract}

Keywords: experience economy, ethnography, management education, speed, storytelling

\section{Introduction}

This paper analyses the notion of speed as a factor in organizational experience. It also presents a research method and learning technique, the co-narrative method, developed to capture varieties of individual experience of shared events. Our contribution is thus two-fold: firstly, we examine the notions of speed and slowness in management and experience economy, based on a field study conducted through the conarrative method. The study comprises of researching seven different festivals, and its results are presented in the form of a conversation between characters of FAST and SLOW: epitomes of different attitudes towards the speed of experience created to aid our field research.
Secondly, we identify some of the deficiencies of current management education practice and, building upon insights on the possible contribution of the humanistic approach (Gagliardi and Czarniawska, 2006), we utilize our specific focus on the fast and the slow side of organizational and festival experiences to propose the co-narrative method as a management learning technique enabling managers and management students to explore the theatricality of such events without losing their enthralling complexity.

We begin by exploring the positive and negative interpretations of speed in social theory and management literature, and the organizations presented as exemplars of speed or slowness. Yet in our reading, this double valuation should not be seen as evidence of two mutually exclusive paradigms, but of two modes of experience, 
focusing on different aspects of organizational life. In order to highlight this, we examine the notion of the speed of experience in the light of the idea of experience economy - a new type of market orientation, or perhaps a changed perspective on retail transactions proposed by Pine and Gilmore (1999). In experience economy, businesses strive to simultaneously achieve a high degree of product differentiation and mass customization. The resulting transactions are viewed as theatrical spectacles, aiming at providing clients with unique experiences. They are often defined by their transience, with their most important effects enduring only in the minds of the participants (Johansson and Näslund, 2006).

Studying such events, understood as stagings (Pine and Gilmore, 1999) that can be of prolonged nature, such as in emerging entrepreneurial events (Johannisson, 2005), demands the development of methodological approaches and research methods capable of encapsulating the subtler nuances of experience economy interactions such as continuity captured through momentary events or repetition defined through difference (Bill, 2006). Such methods would be useful both for research aimed at understanding transformations of contemporary organizations and marketplaces, and for management education, helping to promote understanding of organizational and event experience. The finding of such methods is the main aim of our paper.

We chose the experience of speed as the thematic framing for our study, because it is one of the important management ideas and has emerged as one of the defining axes for describing contemporary culture, appearing in descriptors ranging from Fast Food, Fast Talk (combined in a title of Leidner's 1993 ethnographic study) and Fast Company (a business magazine already in its fifteenth year of circulation) to its opposites in Slow Food (a celebrated movement that "brings together pleasure and responsibility"), slow architecture (a manifesto and accompanying website issued by a group of Dutch architects), and just general Slowness (proclaimed in Kundera's 1995 novel). Relatedness of these issues can be examined in a variety of ways, but what we find particularly interesting is the ambiguous valuation given to speed by different theorists and thinkers, often in very similar contexts. This is by no means a new phenomenon: the pensive flâneur of Baudelaire and Benjamin, strolling through the city at the dawn of the last century was bound to have collided with Marinetti's futurists attempting to run by with "the racer's stride" or drive by in "a racing car whose hood is adorned with great pipes, like serpents of explosive breath." (Marinetti, 1909).

\section{Speedup}

Marinetti, the Italian futurist poet believed in the gospel of speed. In his Manifesto of Futurism (1909) he exalts in its beauty and energy:

We affirm that the world's magnificence has been enriched by a new beauty: the beauty of speed. A racing car whose hood is adorned with great pipes, like serpents of explosive breath - a roaring car that seems to ride on grapeshot is more beautiful than the Victory of Samothrace (ibid.).

More contemporarily, authors such as Virilio (1997) or Baudrillard (1992) proclaim the near infinite speedup of the social, of which they are both deeply wary. Virilio considers speed one of the main characteristics of and a major problem to contemporary society. Speed disorientates people and deprives them of history, as history happens in time. Instantaneity globalizes time, distorts it and removes space for things to happen in local spaces and frames. Existence, on the other hand, is situated here and now, and the pace of virtualization poses a threat it, as it disconnects communication from the here and now. Its speed disintegrates human beings and the way they work in a society. For Baudrillard (1992), the modern speed of information has annihilated time, denying delay, creating constant instantaneity. Such time happens outside of the human frames of existence, heading for an apocalypse where several moments co-exist and produce a kind of artificial immortality. Both Virilio and Baudrillard consider speed something typical of our age, inevitable and rather sinister.

And yet, much of managerial discourse remains thrilled by the idea of ever-accelerating speed. Jones (1993) and Cushman and Sanderson (1996) promote high speed management (HSM) as a response to the ever-changing environment. Time based management strategies are aimed at working faster than the competition, knowing that time is money and using time as a most valuable resource. All processes, including managers' work and the culture of the companies, should be sped up, making way for rapid innovation, speed to market, and instant adaptation processes. Mourier (2001) proposes to complement this by velocity management, based on "decision making at lightning speed" (p. 24). 
The popular business press emphatically echoes this fascination with speed. Speed benefits the team spirit in software firms and slowing down can cause losses of clients and brings down morale (Dahl, 2009).

This approach to management is seen as allencompassing: not only organizations profit from high speed. For Kozminski (2005), high-speed management, coupled with flexibility, forms a suitable template for systemic transformation of the European economy, allowing the fastest-reacting performers win the competition game in the changing world. Such strategies demand flexible labour markets to which people and companies need to adjust. This calls for management education programmes geared to train niche finders, able to identify and exploit transient opportunities in the market. Such programmes should promote speed and flexibility through the ability to adapt instantaneously and cope with radical change. Child and McGrath (2001) see speedup as embedded in the ongoing transition from a materials-based economy to one based on flows. Organizations have broken free of physical constraints and velocity has become one of the main challenges facing them, together with interdependence, disembodiment and power. The altered conditions promote organizational forms better suited to the speed at which the environments in information-intensive economies work, and call for managerial ability to withstand and exploit constant change (Doyle, 2002; Kozminski, 2005).

Things as well as people should be managed as fast as possible - methods such as Just-in-Time delivery aim at speeding up operations, ideally to the level of instantaneity, via perfect coordination (e.g. Zimmer, 2002). Their scope encompasses all organizations, including those from outside the material production sphere, such as knowledge intensive firms (Davenport and Glaser, 2002). Slowdown is a condition to be abhorred, whether it applies to market growth (Dawson and Larke, 2004) or theory generation (Burton, 2005).

\section{Slowdown}

However, not all students of contemporary organizations are as enthusiastic towards speed. Purser (2002) argues that management decisions should not be made impulsively or on demand as important issues need time to be thought through. Decision making should take the future and the past into consideration, something that the current trends to speed up, creating “prolonged present” (p. 156), do not allow for. Enron, as described by Roberts and Armitage (2006), can be seen as a pertinent illustration of what can happen if speed takes precedence over reflection. The company, ultra-fast in its appearance as well as disappearance, still caused gigantic problems in its wake. The authors describe Enron as

an impermanent organization and an organization that is almost wholly determined by its relationship to the excessive speed at which it operates in relation to its environment (ibid., p. 564).

Holmqvist (2009) notes another pathological side of organizational speed: it can limit the ability of organizations to learn, as learning is invariably based on interpreting experience. Hurrying that process upsets the balance between exploring and exploiting experiences, leading to learned solutions that turn out to be ineffective or just plainly wrong. To circumvent this the author suggests a slowing down of organizations by "complicating" them, i.e. making their learning processes more involved through interorganizational collaborations. Hensel (2011) argues that management consulting should take time, too, as good consulting practices benefit from a prolonged contact with the organization, metaphorical thinking and reflection - shortcuts are a sure way to make mistakes (Hensel, 2011). Davis and Atkinson (2010), writing in Harvard Business Review, similarly propose that space for reflection is needed in order for companies to achieve high performance. Indeed, strategic speed is different from operational speed and depends on allowing for slowness.

$[\mathrm{P}]$ erformance suffered at firms that moved fast all the time, focused too much on maximizing efficiency, stuck to tested methods, didn't foster employee collaboration, and weren't overly concerned about alignment (ibid., p. 30).

Other authors go even further. In two related interventions, Case et al. (2004, 2006) radically criticize not only the assumption that speed is good for organizations, but, indeed, that it is necessary. Other authors, most notably Honore (2004), not only present a critical stance towards speed but unequivocally praise slowness as simply better. Humanity, Honore argues, has been trapped in a self-proclaimed dogma of incessant acceleration, with speed becoming an addiction, and every day turning into a race. This constant living in the fast lane makes our experiences superficial, takes a toll on our relationships, and drives us towards a kind 
of existential stalemate. Slowness is an essential feature and condition of enjoyment.

\section{Fast or slow organization?}

Numerous examples of fast organizations, and some description of slow ones, can be found throughout organization studies literature. We briefly present a few better known ones, in order to sketch the framing of organizational realities which we wish to contrast to our approach. Strannegård and Friberg (2001) tell the story of the aptly named Quickompany, a rapidly developing IT firm where play and work intermingle and in equal measures contribute to the company's success. Its employees are all relatively young and dedicated to their job. They do not feel comfortable in traditional, structured professions, preferring the challenge of chaotic, high-speed environments. The constant creative change is, however, not regarded as exceptional by the employees; it is "business is not as usual" (p. 40). This can be explained by the industry that Quickompany operates in: IT. Computer games and playing with technology are part of the everyday routine, just like writing programs. Slowness: lengthy decision-making processes, protracted pondering, and pure idleness are the cardinal sins in this company. The employees say that they love Quickcompany while the authors believe that the organization is a foretaste of what management might look like in years to come. YalaYala (fast fast in arabic), described by Boutaiba (2004) is another small start-up company from the same industry. Its headquarters sport a poster saying "Speed is God and Time is the Devil”. Its employees, a group of very creative people, are consciously trying to create a non-traditional company where they can all do the sort of work they really like. They insist on remaining the same persons at work and outside of it, and being fast is one of their distinguishing traits, closely linked to their entrepreneurial spirit. They are always ready to let go, to begin anew, and on the whole "YalaYala's way might be referred to as the way of the moment" (ibid., p. 33), and its culture as "a world of suddenly (ibid., p. 34). The extraordinary level of diversity within the company, as well as the strength of the tolerance for differences is equalled only by the pace at which the firm operates; speed is seen to bring the freedom that the founders value so much.

Leidner (1993) depicts two much more traditional fast organizations. McDonald's, the fast food company, demands fast, highly routinized work and sets out to control its employees' behaviour. Combined Insurance wants to instil a commitment and motivation into its employees that could be then "carried home" to create a connection to work even in their free time. They both do so through introducing routinized, energetic ways of talking and interacting with potential clients. Routinization, including high speed, is not necessarily opposed by the employees. At McDonald's, it gives them space for personal thoughts and interactions, and makes their job easier; at Combined Insurance it boosts their confidence and offers psychic protection from the burnout that the job may bring. Similarly, in Burawoy's (1979/1982) factory study, the workers work at a high pace, without resisting managerial pressures to speed up, because they create a game of meeting quotas and trying to avoid monotony at work. They abstain from working too fast, because that would cause a rise in quotas and result in a need to work harder for the same amount of money. But within the limits of the current quotas the workers put in effort that cannot be sufficiently explained by the purely financial motives that Frederick Taylor (1911) ascribed to them.

On the opposing side of organizational experience, Miele and Murdoch (2002) present a case study of a Slow Food restaurant. Sardo, the director of Slow Food International, an umbrella organization created to promote the idea of slow eating, is quoted to say that Slow Food can both be seen as a way of protesting against standardization, and as a way of bringing the pleasure of food to the public. McDonald's fast food restaurants are seen as a threat mainly to popular food establishments. Therefore, Slow Food establishments focus on promoting local food culture. Currently the movement embraces restaurants in several dozen countries. The authors describe the Bagnoli restaurant as an example of the movement, as it "embodies the principle of 'slowness' in its adherence to typical cuisine, in its use of local materials and products, and in its ambience of relaxed conviviality" (ibid., p. 318). The restaurant operates since the mid-60s and is a local business located on the coast on Tuscany. The current owner and chef joined the Slow Food movement with the ambition to do something different, "less intensive and more interesting, more creative" ibid., p. 320). The restaurant has traditionally based its cuisine on products from the local forest and continues to do so. It has grown more sophisticated since the joining of the movement but remains a local restaurant, accessible to 
all classes. It offers its guests an experience, which is an effect of and an element in a rich social network. Seen in this context, it operates in a slow way indeed, even if the end process consisting of serving the food to customers does not necessarily last very long.

Speed of organization, is thus not an independent characteristic, but one defined by the frames of reference (Goffman, 1974), or modes of experience of its participants and observers. And the notion of speed of experience is always relative, discernible only in relation to other, slower or faster experiences (Lefebvre, 2004 describes this in terms of relativity of rhythms). This is particularly evident in the forms of organizing that foreground individual experiences, such as festivals to which we turn in the next section.

Paul Ricoeur (1985/1988) proposed that narrative has an ability to represent the experience of time. Time can be experienced in two ways: the cosmological, which is linear, as a progression of events and moments, and the phenomenological time, which we make sense of in terms of the past, present and future. Human time combines and embraces both these ways Ricoeur argues that narratives are able to use this complex character of human time, because of they are based on configuration and interpretation, where tension is a plus, not a lack. In fact, narratives create a "concordant discordance" or a dialectic based on simultaneous individuality and unity with others of the character and his or her experiences, where life is seen as a temporal totality. Ricoeur argues for an active involvement of the reader in the process of creating a linkage between the narrated and experienced reality.

\section{Experiencing festivals - fast or slow?}

Experience economy is a catchphrase associated with a type of traditional organized event, often recurrent (Marling et al., 2009) that is becoming increasingly popular as a template for management in a wide variety of settings (Pine and Gilmore, 1999).. Gilmore and Pine (2007) emphasize that not only firms and management canons change with the introduction of the experience economy, but so do popular expectations. Customers now seek products that fit their way of interacting with the world and which they can incorporate as a significant part of their lives. The product is staged in a performance that strives to engage both parties: the customer and the employee. Festivals, as always potentially (though not necessarily) recurrent events, expressly created, staged, and marketed as memorable (Johansson and Näslund, 2006) are often touted as exemplars of the experience economy approach (Lorentzen, 2009; Johansson and Kociatkiewicz, 2012).

Hjorth and Kostera (2007) argue that experience economy is based on four principles: immediacy, subjectivity, playfulness, and performativity. Experiences are always embodied and contextualized, never abstract, and so the experience economy product needs to be immediate, situated in concrete time and space. This includes individual modes of experiencing, such as fast and slow, which need to be taken into consideration. Subjectivity means that experiences always have an active subject, engaging with the process and transforming it, while being transformed him- or herself. The speed of experience is thus crucial in defining the product in its double life of immediate perception and potentially treasured memory. Authenticity of experience does not mean earnestness; experience economy performances are playful, thriving on the ironic distancing towards the activities. The customers are ideally aware of the staging and do not take it utterly seriously. The whole interaction is about having fun. Finally, performativity of the economy means that the products are being created "on the spot", they are realized as they are experienced, which may mean fast or slow depending on the consumer's preferences. It is impossible to store experiences or to recycle them. They come and are they are consumed fresh.

Hjorth and Kostera also point out that there are different scales of experience production, from unique through mediated to mass-produced. The products are in all cases equally subjective, immediate, and performative, but they may be presented as belonging to different experiential scopes. The unique product is one of its kind, such as for example in art production. The mediated product is an experience of one kind transformed into another, as in design the ordinary is changing into the aesthetically sophisticated. Finally, mass-produced experiences are shared with many others, as in the case of e.g. sports spectacles. Depending on the type of practice, customers are invited to be introspective or extroverted in their experiences. Yet in all types consumption takes the form of a quest - for adventure as well as for identity.

Experience economy operates in a variety of rhythms, and its events can be understood as slow or fast depending on the inclinations of the participants rather than any definite features of the events themselves. Thus, 
a Volkswagen factory in Dresden has been described as a clear example of experience economy approach (Hjorth and Pelzer, 2007): this Transparent Factory (its official name) allows prospective customers as well as tourists to watch the entire manufacturing process, and gives the buyer the possibility to follow one's ordered car from its inception right to the handover of the finished product. The process embodies both a speedy creation of a fast vehicle and a slow process of familiarization with one's automobile-to-be.

These insights form an additional incentive towards developing methods of management education suitable for experience economy events. We believe that the dialectic of speed, while crucial for the operation of the experience economy, is neither commonly understood nor taught. To conceptualize it, we set out on a mini-ethnographic journey of our own, focusing on the rhythms of experience and subsequently on the possibility of expressing them through storytelling.

\section{Co-narrative study}

For the field study of the themes of speed and slowness, we chose to use the co-narrative method, the development of which forms one of the contributions of this paper. Situated firmly in the ethnographic tradition in which understanding is arrived through immersion in the studied culture, allowing the researchers to study phenomena in their living context (Agar, 1986), the co-narrative method is a form of hybrid approach to observation (Leidner, 1993), also involving multiple researchers and building upon the awareness that research results an reported understandings cannot be divorced from the subjectivity of the ethnographer which provides the only means for perceiving, interpreting, and reporting the studied culture (Behar, 1993).

In the co-narrative method, hybrid observation means a mixture of participant and non-participant observation, where the former implies the taking upon oneself of roles from within the studied field, and the latter means not taking upon oneself any such roles and thus remaining an outsider (Kostera, 2007). Embracing this paradox, co-narrative researchers consciously take upon experiential roles, or modes of experience predefined outside the field, and use them to steer and enhance their observation. In our study, we adopted for the duration of the observations the antonymic personages of Fast and Slow, created specifically for this study but representing, in only slightly abstracted form, the temperaments of the authors. This is a kind of reflexive ethnography (Davies, 2007), undertaken with the purpose of method development through (inter-) subjective experience. Study of other phenomena would require adopting different experiential roles.

We carried out a narrative study of seven different festivals based on hybrid observation (Kociatkiewicz and Kostera, 2010). In most ethnographic studies, directly experienced situations, interactions, personally made observations and interviews, as well as jotted down field notes are collected and created. When the researcher leaves the field, they are subjected to theoretical interpretations (Rosen, 2000). Co-narrative study focuses on collecting experiences and while other forms of assembling evidence (notes, photography, video recording) are encouraged, care should be taken so that the latter do not interfere with the former

We took only sparse and sporadic notes during the events. Taking cues from the narrative tradition of organization studies (Gabriel, 2000; Boje, 2001), the co-narrative approach centres on allowing researchers to reflect on their experiences, and to present them as a more structured narrative of the entire study experience. We believe, as does Czarniawska (1997), that organizing may, with advantage, be seen as a kind of storytelling; The result of the study of organizing may also be fruitfully presented in the story form. The stories of our report are personalized and told in first person singular in order to emphasize the subjective quality of experience (Hjorth and Kostera, 2007), but the choice of the narrative form should reflect the particular focus of the specific co-narrative study.

Such stories are a form of interpretation and theorizing, and simultaneously a means of capturing the personally experienced dimension of our study. Van Maanen (1988) labels them the impressionist tales, that is, tales that "evoke and open, participatory sense in the viewer [...], startle complacent viewers" (p. 101) and engage the reader with the field. They consist of "words, metaphors, phrasings, imagery, and most critically, the expansive recall of fieldwork experience" (ibid., p. 102). The aim of the author is to produce a feeling of "having been there" in the reader. For this reason, they can facilitate the sharing of organizational experiences that is the central aim of the co-narrative approach.

During this research project, we have observed seven festivals in three different countries, taking place during one year (2010). We collected impressions and 
documented our observations through photography used as sensual note taking (Warren, 2008), simultaneously promoting careful observation and enabling re-experiencing of past moments (Berger, 1980). In this paper, we present our narratives from a single festival, chosen to illustrate our experiences in the field as well as the co-narrative method we propose for experience economy-based management education.

Our narratives of the studied events, written down afterwards, reflecting on and retracing our experiences of the studied festivals, are inspired Baudelaire's and Benjamin's meandering reflections on urban strolling, as well as the research techniques of Michel de Certeau (1984/1988). They are the end result of our research rather than field notes in need of explication.

\section{The characters}

FAST is shooting from the hip, catching moments that lack dimensions, taking photos that are perhaps attempts at puncturing the fabric of reality. Whatever will emerge from the holes? Lacking time, they are not really passing moments, rather glimpses of instantaneous eternity. Not pausing to evaluate or compare, she is already elsewhere (Strannegård and Friberg, 2001), dislocating the experience from the frame, exposing the subliminal messages under the blink, always one step ahead of herself.

SLOW embraces patience, deliberation, and reflection. It is to live through each moment as it comes, savouring time in its sequence and succession. It is to allow oneself the leisure of coming to grips with one's sensations and feelings. It is to pause, choosing the exact words that can capture all the hues of the described situation. Slow is analytical, and careful in his observations. He sees experience economy as a further opportunity to explore minute facets of existence, taking delight in the details of each performance. He is aware that reflection is no defence against cliché.

\section{Medieval fair: The stories}

FAST. The sounds blend and fuse together: human voices, the shrieks of children, sounds of various instruments, and something like repetitive tapping of wood against wood. After the relative orderliness of the queue at the entrance, the streams of people mingle and shift. Everyone is on their way somewhere, around the tents placed all around the green area around the castle. A woman dressed in a long black velour dress and a hat. A man in a long off-white shirt and brown trousers, a small child in a dress, holding its rim to her breast. Birds of prey - they keep still, watchful. Oh, they are attached to poles by the foot... Poor things... A puppet dragon gaping at a group of kids sitting down in front of the puppeteers' stage, screaming with delight. A man drinking mead. A child falling on its bum. A woman in a long green skirt playing the violin while a group of men in velvet hats sing. A young woman driving her baby carriage right into the crowd. A man squatting down, pausing to deliberate over some bottles of liquor; I look over his shoulder. The labels say these are elixirs. A spirited storyteller draws applause from an enchanted audience. Here I linger a little while longer, he glimmers in front of me, shapeshifting, magnetic, carrying us away into world of his stories. Barefooted drummers stomping and shouting, while tapping their drums. Smells of woollen cloaks and smells of roasted meat, sweet smelling buns and bitter of the metallic surfaces where they are served. Everything moves, even the stands seem to flicker in the powerful sunlight. I float, I skip, I swirl, with and against the others, around the stands, around the performers. The place and people betwixt and between: past and present, distant and close, fairytale and reality all overlapping and pulling apart, indefinite, neither-nor, and-or. The sounds of flute and of human voices softly pour through the space, curling around the trees, stalls, tents, towards the centre. SLOW. It is high spring, and the weather is glorious: the sun is bright, the air is warm, all the vegetation lusciously green. The festival, organized in a park in the middle of the town, seems a natural fit with the surrounding greenery. It is an annual event, and this is the fourth time I attend this festival. Almost all of the stalls and performer tents look enticing, but I take my time walking around, familiarizing myself with the layout and breathing in the general atmosphere before approaching any of the sellers or artists. There is a fairly large and varied crowd milling about: a lot of families with children, quite a few childless couples and small groups of adults. Not too many solitary visitors, it appears. Most of the guests are dressed in everyday clothes, but a few wear pseudo-medieval clothes: tunics, gowns, dresses, and peasant shirts. As each year, I am enthused by the peacefulness of the presentation: there is a display of sword-fighting and an archery competition, but the vision of middle ages re-enacted here is not military at its core: there are many more 
musicians, storytellers, shopkeepers and food vendors than knights and archers. I like that a lot.

There appears to be no centralized timetable of performances available, but by walking around I begin to assemble a timetable for the few hours we might spend here: a storyteller, my very favourite entertainer of the show, performs every hour, then there is a musical show every 45 minutes, a puppet theatre play, and a live action play I would like to see. Putting them together creates a leisurely rhythm for moving about the festival space, with periods of focused attention interspersed by aimless wandering and browsing through the displayed wares.

The quality of performances, and of the products on offer, is quite varied. One group of musicians seems quite skilled and well-rehearsed, while others sound rather amateurish. The difference in skill between two storytellers is also quite noticeable. Products sold range from tacky plastic swords and shields to elaborately presented potions boasting tongue-in-cheek miraculous effects. There is a falconry display bringing together twelve different birds of prey, but they are tied to their posts and appear much more pitiful than awe-inspiring. FAST convinces me to have a go at 'Splat the Rat' a game of skill where the punter tries to hit a plush rat with a wooden mallet. Inevitably, I am too slow to win.

\section{Telling intertwined stories: To explore and to learn}

What do we make of those tales? How do they relate to organizing and organizations? Below, we present our individual reflections on and common interpretation of the stories, and argue why we believe the dialogue can be important to others interested in experience economy events.

Throughout the study we assumed the characters of FAST and SLOW to guide our experience of the field. The choice was inspired by Jung's (1968) notion of archetypes: patterns located in the collective unconscious and containing images related to human motivations and inspirations (Jung, 1968). Jungian archetypes are used in studies of organizations to depict and interpret hidden and dark sides of organizations (e.g. Bowles, 1991; Carr, 2002; Kociatkiewicz and Kostera, 2010), to explore the inspirational potential of images of heroes, heroines and villains (e.g. Bowles, 1993; Aaltio, 2008), to narrate mythologized aspects and qualities of organizations (e.g. Kociatkiewicz, 2008; Parker, 2008), and to seek inspiration for motivation and engagement in change processes (e.g. Matthews, 2002; Hatch et al., 2005). The archetype can serve as plot, character, place or time of action. Tales containing, or based upon, archetypes, have the potential to profoundly move the listener or reader, inspire and explain important aspects of reality (Kostera, 2010; Kostera and Postula, 2011). In the context of this study, our aim is to allow us to focus on the differences, rather than commonalities, of our experience, and to reflect on the role of speed in focusing our attention.

\section{Reflections}

FAST. To me, the festivals where first and foremost about flows and streams: of people, smells, sounds, impressions, moving about at a rapid pace, differing from festival to festival, both as to their contents and feelings that the following of them evoked. Festivals differ: some are playful, melodic, some chaotic, hectic, intense. Experiencing them meant for me moving along their characteristic streams, getting involved with their rhythms and letting myself co-oscillate in synch with their vibes. The experience was a melange of impressions taken in by all senses at the level of some common denominator that they have, a stratospheric and ultrafast which sets the nerves alight, which only brushes against the matter they are made of and electrifies it like trance, like music, like a dream of finding a hidden way. The fast speed at which I experienced the festivals made it possible for me to catch the moment, immerse myself in the infinitesimal now which then expanded into something my own size, whatever that means, a bubble of time and space where I could encounter the others and witness others' encounters. Experiencing fast, so fast that it transcends human capabilities of sensing, breaking the barriers of matter makes it possible to lift, to take flight - like ducks do, when they alight from an ultra fast run on the surface of a lake. These were immensely enjoyable and powerful experiences. Yet even more enjoyable and perhaps somehow enlightening was the encounter with SLOW's mode of experiencing, the clash between our visions and the unlikely synergy of them on a level that was new to me, fresh, making me feel as curious and lively as a child. Learning about his way of seeing them was like gaining an extra dimension to the time that passed, as if discovering the undercurrent 
negating its linearity, revealing the hints of its many regions and depths.

SLOW. Festivals of any kind are, for the visitor, the embodiment of the Bakhtinian (1941/1984) carnivalesque: a time and space separated from the everyday routine, accessible only on specific, and relatively rare, occasions. But they are also cyclical, repetitive events that repeat, with only slight variance, patterns from their previous incarnations. The experience of the festival is thus intimately connected to the patterns of the quotidian life, and to the memories of previous fairs. But at the heart of each repetition, as Deleuze (1968/1994) famously pointed out, lies difference: the unexpected disruption of the status quo. And much of the enjoyment lies in being able to appreciate such novelties, the variations from the norm that form different, and more complex rhythms. The difficulty, as Lefebvre (2004) noted in his Rhythmanalysis, lies in aligning the different rhythms structuring out life into a coherent, isorhythmic harmonies. This is the dialectic between SLOW and FAST experience, between catching the moment and reflecting upon its context. This is wisdom which come, if ever, with age. And ageing is a slow process.

\section{Interpretation}

Festivals are not just gratifying on the individual plane, but may bring something quite valuable when shared. Here again, the archetype-based framework can help in finding a way to connect disparate experiences, as archetypes, providing links between the individual and collective domains, have the capacity of facilitating the turning of individuals into groups.

An archetype of the joining of opposites is the syzygy, or the alchemical wedding. Usually it is the effect of uniting the archetypes of the male and female aspects of the soul: animus and anima (Jung, 1968). Such unification is a source of great power, and it also symbolizes communication and completion. It brings together the conscious and unconscious minds and domains and thus produces an enormous amount of inspiring energy. Through syzygy, different individualities are joined but without the loss of identities. It has the power of transformation and fulfilment and is enormously inspiring and creative. We regard the coming together of FAST and SLOW experiences as a syzygy, though we would not like to link them to genders or associate them with the qualities of Anima or Animus. To achieve syzygy, more than just a variety of experience is needed. It requires a conscious and purposeful act of sharing. This resonates strongly with Emmanuel Levinas' (1969/1999) notion of responsibility for the Other. Encountering the Other brings forward a responsibility that is central to our being. It is through the relationship that an idea of infinity is produces. The other is separate from the self and is everything other than the same. Encountering the Other is a transcendent experience, from which language and the notion of truth spring. Our humanity begins with responsibility for the Other; encountering the face of another makes it possible to transcend our identity and embrace a responsibility which is infinite. Thus it works as the archetype of syzygy, where the moment of encounter of two disparate beings gives rise to transcendence of the limitation of the "I". Like for Levinas, this is a kind of movement outside of the boundary of the "I" that precedes reciprocity, a movement towards the Other that can be experienced as profound compassion. For Levinas moral feeling is more important than moral theory. Likewise, embracing the archetype of syzygy means encounter before reasoning, experience prior to any reflection or self-reflection. Recognition can only take place after the fact, which changes the presence, as it becomes extended by the awareness of the Other, and also the past, setting free meanings of events of the past and thus changing the past itself. This temporality of responsibility also describes syzygy - the alchemical union which transmutes time in all directions.

Everyday life, Lefebvre (2004) noted, is simultaneously governed by the homogeneous and desacralised clock time, used to organise work and leisure and to push for ever greater efficiency, but it also

remains shot through and traversed by great cosmic and vital rhythms; day and night, the months and the seasons, and still more precisely biological rhythms. In the everyday, this results in the perpetual interaction of these rhythms with repetitive processes linked to homogeneous time (p. 73).

Correspondingly, festivals, albeit specifically set out from everyday experience, are shot through with fast and slow rhythms, and organizational events lending themselves to different speeds of experience. This means not only that it is possible to see them as simultaneously fast and slow, depending on one's frame of reference, but also that sharing the divergent experiences through exchanging stories provides a richer, and often unexpected, knowledge. 


\section{Management education}

Recent criticisms of current management education practice and its role in promoting genuine knowledge can be roughly divided into three general threads. The first is the identification of a moral lack. Thus, Höpfl (2005) points out that the current management education almost completely lacks attention to attributes such as compassion, moral judgment or the ability to deal with a complex reality. Hendry (2006) holds a similar opinion, claiming that such qualities as belief and conscience are not developed in the course of education. Other authors focus on the questionable value of the knowledge provided by the prevalent modes of education. D'Andrea Tyson (2005) enumerates lacks such as: no scientific method, excessive focus on knowledge rather than skills, questionable relevance of knowledge. Czarniawska (2005) argues that current management education in the field not only has nothing to do with the current state of research in this area, but often it is clearly inconsistent with it. Students are taught about a non-existent world which may improve their mood, but does not help deal with problems after graduation. MBA programmes have been criticized as unrealistic from the point of view of the business world, detached from reality and context, and imbued with the ideology of control, decision making, individualistic heroism and hierarchies. They are too specialized and fail to learn to develop sensitivity to other people (Mintzberg, 2004). The third problem is the relationship between outcome and method, for example O'Doherty and Jones (2005) argue that education has become a machine for producing sick and irrelevant detritus, justified as 'practical' and glossed up as "business relevant"' (p. 1). Grey (2004) points to the irrelevance of management studies for the work they perform after graduation, while it is very important for most people that they physician holds a degree in medicine, it is completely uninteresting if their superior has a diploma in management. At the same time, management education institutions emphasize the importance of what they see as "practicality" of their programmes. While the fundamental core values in medicine (life, health) are almost universal, in the field of management they are at best debatable (productivity? profit?). The techniques in management are not as broadly recognized and accepted as in medicine and patterns to follow are few. Meanwhile, teaching methods in management seem to be based on the erroneous assumption that these foundations are similar in management and medicine. Thus they prove to be inadequate, even the most realistic of them, the case study, is based on the idea of repeatable solutions and that what is effective in one situation will also work in another. Management education does not make students better managers.

These shortcomings combine and overlap, and we share theview that they areall prominentlacks of contemporary management education. In particular, when teaching experience economy, we experience problems that can be connected to two of these deficiencies: the moral and the methodical. The mainstream teaching material (such as: textbooks and lectures, Czarniawska, 2005; case studies, Grey, 2004; classroom discussion, Böhm, 2005) fails to engage the students in a holistic moral way and there we experienced a serious lack of methods which would enable our students not only to develop ideas relevant for the experience economy but also to empathize and endeavour to see the events from the perspective of the Other.

In order to address these issues, we would like to propose the co-narrative approach as a method for management education within the experience economy area which would make syzygy more likely. Hjorth (2003) proposes a narrative approach to learning entrepreneurship, based on Camus' reading of Sisyphus, but focuses on issues specific for the entrepreneurial development such as revolt and transgression from managerial and academic framing. Gagliardi and Czarniawska (2006) and Jones and O'Doherty (2005) address many of the deficiencies of current management teaching practices but are not focused on the specifics of experience economy. Czarniawska and Guillet de Monthoux (1994) and Banks and Banks (1998) propose the use of narratives, focusing on appropriating pre-existing stories for management. However, a number of authors have concentrated how to use more open ended and emerging narratives in the management education context (e.g. Down and King, 1999; Gold and Holman, 2001; Morgan and Dennehy, 2004). It is within this emerging tradition that we position our proposed educational method. It embraces shared storytelling, based on Boje's (2001) antenarratives, or short dynamic stories, often lacking plot, collectively created and exchanged by students or researchers in order to invoke and to perform rather than just tell what happened, where and when. 
While narratives in general can facilitate more contextualized understanding of organized settings (Czarniawska, 1997), co-narratives can inspire their authors as well as their audience to experience unexpected and new modes of learning. The syzygy archetype brings not just mind-opening possibilities, but has the power to transform and revive those that embrace it. People often consciously embrace selected aspects of their psyche, banishing "unfitting" ones, for example, a man may wish to get rid of his feminine aspects. These unconscious parts of the self Jung (1959) identifies as the shadow. People then project all they do not like in their own shadow on others, resulting in animosity rather than empathy, which prevents them from fully living as themselves as well as from truly meeting others. Syzygy makes it possible to encounter oneself and others and to achieve wholeness. This meeting has enlightening and saving powers, which can be seen in religious images, where syzygy expresses the encounter between God and Israel or Christ and his Church (Jung, 1959). The syzygy can be seen as a connecting bridge, not just between people but also between their conscious and unconscious aspects, an encounter that mobilizes communication, imagination, dreams and a sense of profound connection and understanding (E. Jung, 1957). It is thus both highly inspiring and has a great potential for communication. The central role within the method is played by antenarratives (Boje, 2001) which direct people's attention and are experienced and not just cognized. Antenarratives thrive on ambivalence and ambiguity, they are powerful sensemaking devices and can be used a means for sharing and organizing (Magala, 2009). Festival stories, expressing bursts of experience rather than reflexive ruminations, are antenarratives about different festival experiences: fast and slow, brought together in a short learning event instead of traditional "cases". They could be actively collected by students working in groups based on the diversity of experience. The students would attend specific events and write short fragmentary stories, of the kind that we have presented in this paper. The stories need not have an exclusively written form; they can be told orally and accompanied with images and films in the classroom. Instead of seeking for traditional solutions to these "cases" the students could instead try to co-author archetypical stories, like we did in this paper, exploring differences in experience, possibly focusing on speed, and concentrate on the syzygic effects these tales have on the readers, listeners, and authors themselves. Thus the students would have a possibility to explore, discuss and learn about experience economy events such as festivals without simplifying them or depriving them of their contradictions and paradoxes. Experience economy described as different from mass production in that it is "mass customized" and thus individual experience is what lies at its very heart (Pine and Gilmore, 1999). Attempts to simplify and streamline such events fail, resulting in feelings of alienation, impatience, and frustration (Kociatkiewicz and Kostera, 2010). A method of education that attempts at embracing the whole complicated experience as an enactment of the syzygy archetype may be particularly useful for the learning of the staging and coordinating of such activity. Syzygy makes people open to diversity and gives them an impulse to reach out to the Other. It also makes them sensitive to an understanding of different kinds of experience - an understanding which is not just of an intellectual, but also sensual and emotional kind. Teaching through syzygy is like listening to music as compared to having it explained in words. Syzygic teaching can be done through an attention to time, dialogue, rhythm, to be learned from the humanities, Ricoeur argues that narratives present the moments when action is taken, and so they actually place agency within the story. The plot is where narrativity and temporarily meet, enabling immersion and also providing the space for a considerable complexity. Thus streamlining can be avoided without the loss of enjoyment or, indeed, a sense of meaning of the whole. We do not propose to replace more traditional classes but to complement them, and particularly in the area of experience economy management. Such sharing can not only teach us more about experience economy settings, but about ourselves and throw new inspiring light on the benefits of diversity.

\section{Concluding remarks}

What have we learned from exploring the different ways of experiencing festival participation? Having explored the different ways of experiencing festival participation, and having shared our impressions of the exploration, we are still unable to compare the strengths and weaknesses of our two approaches. But such comparison was never our goal.

As much as slowness has been celebrated as more artful, and as much as speed has been hailed as more modern 
and progressive, without the normative frames, they are just two ways of engaging with the world. Perhaps alternative ways: like two parallel lines they mark different experiential paths that cross in infinity. Or in the syzygy of ethnographic conversation, like the one in this paper.

The co-narrative method, aimed at encouraging syzygy, offers a means of helping to further and inspire processes of contextualized learning. According to Ricoeur (1985/1988), an active collaboration between the narrative and the reader is important in the interpretive process, a story has to be integrated into one's experience of life and self. Stories can be re-interpreted with time and can help readers redescribe their experiences. But the co-narrative method, juxtaposing different modes of experiencing the same event, makes it possible to bring in the experiences of co-narrators into the process of redescription, extending one's understanding beyond the solitary viewpoint.

It is thus a Ricoeurian interpretive process on fast forward, or a simultaneous process of learning from mutual re-interpretation. The understanding offered is not only intellectual, as redescription of the past may bring hope and thus a new imagining of the future. Syzygy can bring participants closer to Levinas' $(1969 / 1999)$ ideal of responsibility for the other. Shared, though often radically divergent vision promises more empathy and compassion; this in itself would be a most desirable effect of a humanistically oriented learning process. The co-narrative method offers a means of classroom learning that is not just suited for learning about experience economy events but has a moral effect as well. It addresses all the three main lines of criticism directed toward management education that we presented earlier. Firstly, it puts moral issues such as compassion and moral judgement into focus. Secondly, it enables teaching of knowledge relevant to one current area of management (experience economy). Thirdly, it is not based on the assumption of a universality of values and techniques, but quite the opposite, on the recognition of the value of diversity. In all, it is a realistic teaching method which does not presume that solutions can be transplanted into different situations but where the solution is secondary and based on the ability to empathize with the Other.

The co-narrative method can be used in experience economy education for practical reasons (its closeness to experience), but also for teaching CSR and business ethics in accordance with Bauman's (1993) idea of morality as responsibility to others rather than obedience to rules. Such a morality can only be grounded in the "moral impulse", which precedes rationality and reason. We believe that a syzygic approach to education can encourage the use of this impulse. It will not reverse the division of labour, which diminishes responsibility, but it may defeat some of its effects by making students sensitive and positive towards diversity of experience. To summarize, the theme of this paper is speed, and how experience is both slow and fast. This insight is important for event organization and management, as experience economy is primarily about facilitating experience. We have shown how narratives are suitable for the expression of temporal experience and our key insight concerns the value added by simultaneous narrating in class. This co-narrative method enables a dynamic learning process, open towards otherness and thus suitable for learning of experience economy management. In order to reach its full potential, it needs to be immersed in the context of humanities, where it derives from, as such a context makes it possible to make space for compassion as one of the key learning effects.

\section{References}

Aaltio, I. (2008). 'Louhi, the Mistress of Northland: the power of the loner'. In M. Kostera (ed.) Organizational Olympians: Heroes and Heroines of Organizational Myths, pp. 17-29. London: Palgrave.

Agar, M. (1986). Speaking of Ethnography. Newbury Park: Sage.

Armstrong, K. (2005). A Short History of Myth. Edinburgh: Canongate.

Bakhtin, M. (1941/1984). Rabelais and His World. Bloomington: Indiana University Press.

Banks, S.P. and A. Banks (1998). Fiction and Social Research: By Ice of Fire. Walnut Creek: SAGE.

Baudrillard, J. (1992). The illusion of the End. Stanford: Stanford University Press.

Bauman, Z. (1993). Postmodern Ethics. Cambridge: Basil Blackwell.

Behar, R. (1993). Translated Woman: Crossing the Border with Esperanza's Story. Boston: Beacon Press. 
Berger, J. (1980). About Looking. New York: Pantheon Books.

Bill, F. (2006). 'Experiencing the Dairy: Unlocking the Value of Peripheral Traditions'. In D. Hjorth and M. Kostera (eds) Entrepreneurship and the Experience Economy, pp. 209-228. Copenhagen: Copenhagen Business School Press.

Böhm, S. (2005) 'Zero'. In D. O’Doherty and C. Jones (eds), Manifestos for the Business School of Tomorrow, pp. 206-213. Åbo: Dvalin Books.

Boje, D. M. (2001). Narrative Methods for Organizational and Communication Research. London: Sage.

Boutaiba, S. (2004). 'A moment in time'. In D. Hjorth and C. Steyart (eds), Narrative and Discoursive Approaches in Entrepreneurship: A Second Movements in Entrepreneurship Book, pp. 22-56. Cheltenham: Edward Elgar.

Bowles, M. L. (1991). 'The organization shadow', Organization Studies, 12(3), pp. 387-404.

Bowles, M. L. (1993). 'The gods and goddesses: personifying social life in the age of organization', Organization Studies, 14(3), pp. 395-418.

Burawoy, M. (1979/1982). Manufacturing Consent: Changes in the Labor Process under Monopoly Capitalism. Chicago: University of Chicago Press.

Burton, D. (2005). 'Marketing theory matters', British Journal of Management, 16, pp. 5-18.

Carr, A. (2002). 'Jung, archetypes and mirroring in organizational change management: lessons from a longitudinal case study', Journal of Organizational Change Management, 15(5), pp. 477-489.

Case, P., S. Lilley and T. Owens (2004). 'Organising speed: a quick introduction', Culture and Organization, 10(1), pp. 3-5.

Case, P., S. Lilley and T. Owens (eds, 2006). The Speed of Organization. Copenhagen: Copenhagen Business School Press.

Child, J. and R.G. McGrath (2001). 'Organizations unfettered: organizational form in an information-intensive economy', Academy of Management Journal 44(6), pp. 1135-1148.

Cushman, D. P. and S. Asanderson (1996). Continuously Improving an Organization's Performance: High Speed Management. New York: New York University Press.

Czarniawska, B. (1997). Narrating the Organization: Dramas of Institutional Identity. ChicagoLondon: The University of Chicago Press. Czarniawska, B. (2005). 'Forbidden knowledge: Organization theory in times of transition.' Management Learning, 34(3), pp. 353-365.

Czarniawska, B. and P. Guillet de Monthoux (1994). (eds) Good Novels, Better Management: Reading Organizational Realities in Fiction. Margate, U.K.: Harwood.

D'Andrea Tyson, L. (2005). 'On “Managers not MBAs"'. Academy of Management Learning \& Education, 4(2), pp. 235-236.

Dahl, D. (2009). 'Fast, flexible, and full of team spirit: how to work more like a start-up', Inc., 31(4), pp. 95-98.

Davenport, T. H. and J. Glaser (2002). 'Just-in-time delivery comes to knowledge management', Harvard Business Review 80(7), pp. 107-112.

Davies, C.A. (2007). Reflexive Ethnography: A Guide to Researching Self and Others. London: Routledge.

Davis, J. R. and T. Atkinson (2010). 'Need speed? Slow down', Harvard Business Review, 88(5), pp. 30.

Dawson, J. and R. Larke (2004). 'Japanese Retailing Through the 1990s: Retailer Performance in a Decade of Slow Growth', British Journal of Management, 15, pp. 73-94.

De Certeau, M. (1984/1988). The Practice of Everyday Life. Los Angeles: University of California Press.

Deleuze, G. (1968/1994). Difference and Repetition. New York: Columbia University Press.

Doyle, M. (2002). 'Selecting managers for transformational change', Human Resource Management, 12(1), pp. 3-17. 
Down, J. and J. King (1999). 'Towards a science of stories: implications for management education, Academy of Management Proceedings, B1-6.

Gabriel, Y. (2000). Storytelling in Organizations: Facts, Fictions, and Fantasies. Oxford: Oxford University Press.

Gagliardi, P. and B. Czarniawska (2006). (eds) Management Education and Humanities. Cheltenham: Edward Elgar.

Gilmore, J.H. and B.J. Pine (2007). Authenticity: What Customers Really Want. Boston: Harvard Business School Press.

Goffman, E. (1974). Frame Analysis. New York: Harper Colophon Books.

Gold, J. and D. Holman (2001). 'Let me tell you a story: an evaluation of the use of storytelling and argument in management education', Career Development International, 6(7), pp. 384-395.

Grey, C. (2004). 'Reinventing business schools: the contribution of critical management education', Academy of Management Learning \& Education, 3(2), 178-186.

Hatch, M.J., M. Kostera and A.K. Kozminski (2005). Three Faces of Leadership: Manager, Artist, Priest. London: Blackwell.

Hendry, J. (2006). 'Educating managers for postbureaucracy: the role of the humanities', Management Learning, 37(3), pp. 267-281.

Hensel, P. (2011). Diagnoza Organizacji: Uczyń Pierwszy Krok do Doskonalenia Swojej Firmy. Gliwice: Helion.

Hjorth, D. (2003). 'In the tribe of Sisyphus: Rethinking management education from an "entrepreneurial" perspective', Journal of Management Education, 27(6), 637-653.

Hjorth, D. and P. Pelzer (2007). 'The fate of Phaeton: baroque art for management's sake?', Organization, 14(6), pp. 869-886.

Hjorth, D. and M. Kostera (2007). 'Introduction'. In D. Hjorth and M. Kostera (eds) Entrepreneurship and the Experience Economy, pp. 19-23.

Copenhagen: Copenhagen Business School Press.
Holmqvist, M. (2009). 'Complicating the organization: a new prescription for the learning organization?', Management Learning, 40(3), pp. 275-287.

Höpf, H. (2005). 'Indifference'. In C. Jones and D. O'Doherty (eds), Manifestos for the Business School of Tomorrow, pp. 61-71. Åbo: Dvalin Books.

Johannisson, B. (2005). Entreprenörskapets väsen (The essence of entrepreneurship). Lund: Studentlitteratur.

Johansson, M. and J. Kociatkiewicz (2012). 'City festivals: Creativity and control in staging urban experiences', European Urban and Regional Studies 19. doi: 10.1177/0969776411407810.

Johansson, M. and L. Näslund (2006). 'Artisans of the Spectacle'. In D. Hjorth and M. Kostera (eds) Entrepreneurship and the Experience Economy, pp. 155-180. Copenhagen: Copenhagen Business School Press.

Jones, J. (1993). High-Speed Management: Timebased Strategies for Managers and Organizations. Jossey-Bass.

Jones, C. and D. O'Doherty (2005) (eds) Manifestos for the Business School of Tomorrow. Åbo: Dvalin Books.

Jung, C.G. (1968). 'The archetypes and the collective unconscious'. In H. Read (ed.) The Collected Works of C. G. Jung, vol. 9, pp. 3-41. London: Routledge \& Kegan Paul.Jung, C. G. (1959). Aion: Researches into the phenomenology of the self. New York: Pantheon Books.

Jung, E. (1957). Animus and Anima. New York: Spring Publications for Analytical Psychology.

Kociatkiewicz, J. (2008). 'The cosmogonic duel'. In M. Kostera (ed.) Organizational Epics and Sagas: Tales of Organizations, pp. 142-155. London: Palgrave.

Kociatkiewicz, J. and Kostera, M. (2010). 'Experiencing the shadow: organizational exclusion and denial within experience economy', Organization, 17(2), pp. 257-282. 
Kostera, M. (2007). Organizational Ethnography. Lund: Studentlitteratur.

Kostera, M. (2010). Organizacje i Archetypy. Krakow: Wolters-Kluwer.

Kostera, M. and A. Postula (2011). 'Holding up the Aegis: on the construction of social roles by Polish IT professionals and the change in agency', Tamara Journal for Critical Organization Inquiry, 9(1-2), pp. 75-84.

Kozminski, A. K. (2005). 'Flexibility-based competition: skills and competencies in the new Europe', Human Factors and Ergonomics in Manufacturing, 15(1), pp. 35-47.

Kundera, M. (1995). Slowness. New York: Harper Perennial.

Leidner, R. (1993). Fast Food, Fast Talk: Service Work and the Routinization of Everyday Life. Berkeley: University of California Press.

Lefebvre, H. (2004). Rhythmanalysis. London: Continuum.

Levinas, E. (1969/1999). Totality and Infinity: An essay on exteriority. Pittsburgh, PA: Duquesne University Press.

Lorentzen, A. (2009) 'Cities in the experience economy’, European Planning Studies, 17(6), pp. 829-845.

Magala, S. (2009). The Management of Meaning in Organizations. London: Palgrave Macmillan.

Marinetti, F. (1909). The Futurist Manifesto. [http:// www.unknown.nu/futurism/manifesto.html].

Marling, G., O.B. Jensen and H. Kiib (2009) 'The experience city: planning of hybrid cultural projects', European Planning Studies 17(6), pp. 863-885.

Miele, M. and J. Murdoch (2002). 'The practical aesthetics of traditional cuisines: slow food in Tuscany', Sociologia Ruralis, 42(4), pp. 312-328. Mintzberg, H. (2004). Managers, not MBAs: A hard look at the soft practice of management and management development. San Francisco: BerretKoehler.
Morgan, S. and R.F. Dennehy (2004). 'Using stories to reframe the social construction of reality: a trio of activities', Journal of Management Education, 28(3), pp. 372-389.

Mourier, P. (2001). 'Velocity management: creating organizational instinct', Strategy \& Leadership, 29(2), pp. 24-28.

O’Doherty, D. and C.Jones (2005). 'Inducement'. in: Jones, C. and D. O'Doherty (eds) Manifestos for the Business School of Tomorrow, pp. 1-9. Åbo: Dvalin Books.

Parker, M. (2008). 'Heroic villains: The badlands of economy and organization'. In M. Kostera (ed.) Organizational Epics and Sagas: Tales of Organizations, pp. 105-117. London: Palgrave.

Pine, B.J. and J.H. Gilmore (1999). The Experience Economy: Work is Theater and Every Business a Stage. Boston: Harvard Business School Press.

Purser, R.E. (2002). 'Contested presents: critical perspectives on "real-time” management'. In R. Whipp, B. Adam and I. Sabelis (eds) Making Time: Time and Management in Modern Organizations, pp 155-167. Oxford: Oxford University Press.

Ricoeur, P. (1985/1988) Time and Narrative. ChicagoLondon: Chicago University Press, Volumes $1,2,3$.

Roberts, J. and J. Armitage (2006). 'From organization to hypermodern organization: on the accelerated appearance and disappearance of Enron', Journal of Organizational Change Management, 19(5), pp. 558-577.

Rosen, M. (2000). Turning Words, Spinning Worlds: Chapters in Organizational Ethnography. London: Routledge.

Strannegård, L. and M. Friberg (2001). Already Elsewhere: Om Lek, Identitet och Hastighet i Affärslivet. Stockholm: Raster.

Taylor, F.W. (1911) The Principles of Scientific Management. New York: Harper Brothers.

Van Maanen, J. (1988). Tales of the Field: On Writing Ethnography. Chicago: University of Chicago Press. 
Virilio, P. (1995). 'Speed and information: Cyberspace alarm!', Ctheory [http://www.ctheory.net/ articles.aspx ?id=72].

Warren, S. (2008). 'Empirical challenges in organizational aesthetic research: Towards a sensual methodology', Organization Studies, 29(4), pp. 559-580.

Zimmer, K. (2002). 'Supply chain coordination with uncertain just-in-time delivery', International Journal of Production Economics 77(1), pp. 1-15. 